\title{
Flexural Behaviour of RC Beams Strengthened with Prestressed CFRP NSM Tendon Using New Prestressing System
}

\author{
Woo-tai Jung, Jong-sup Park, Jae-yoon Kang, Moon-seoung Keum, and Young-hwan Park \\ Structural Engineering Research Institute, Korea Institute of Civil Engineering and Building Technology, Goyang-si, Republic of Korea \\ Correspondence should be addressed to Woo-tai Jung; woody@kict.re.kr
}

Received 21 February 2017; Accepted 14 June 2017; Published 17 July 2017

Academic Editor: Peng He

Copyright ( 2017 Woo-tai Jung et al. This is an open access article distributed under the Creative Commons Attribution License, which permits unrestricted use, distribution, and reproduction in any medium, provided the original work is properly cited.

\begin{abstract}
CFRP has been used mainly for strengthening of existing structures in civil engineering area. Prestressed strengthening is being studied to solve the bond failure model featuring EBR and NSMR methods. The largest disadvantage of the prestressing system is that the system cannot be removed until the filler is cured. This problem lowers the turning rate of the equipment and makes it limited to experiment, which stresses the necessity of a new prestressing system. Therefore, the present study applies a new prestressing system which reliefs the need to wait until the curing of the filler after jacking to the prestressing of NSMR and examines the effect of the prestressing size and location of the anchorage on the strengthened behaviour. The experimental results show that the crack and yield loads increase with higher level of prestress, while the ductility tends to reduce, and the anchor plate should be installed within the effective depth $d_{s}$ to minimize the occurrence of shear-induced diagonal cracks. The comparison of the experimental results and results by section analysis shows that the section analysis could predict the maximum load of the specimens strengthened by prestressed NSMR within an error between $4 \%$ and $6 \%$.
\end{abstract}

\section{Introduction}

The conventional construction materials that are steel and concrete have been exploited as the most popular and universal materials for the construction of structures to date. However, the increase in length and size of recent structures together with the corrosion and heavy weight problems inherent to these conventional materials surge the interest in alternative materials enabling us to supplement such problems. Accordingly, Carbon Fiber Reinforced Polymer (CFRP) is attracting attention as a construction material enabling the replacement of the conventional steel materials. CFRP is a composite material fabricated by using polymer resin as matrix and fibers like carbon fiber as reinforcement. CFRP exhibits outstanding resistance to corrosion and high strength compared to its weight. In the construction domain, CFRP started to be used for the repair and strengthening of structures since late 1980s and has recently recognized wider exploitation by replacing steel reinforcement and tendons as well as structural material for bridge decks in newly built structures [1-4].
Concrete structures degrade with time and the serviceability deteriorates following the ongoing performance loss of the concrete member and the material itself caused by environmental actions even though concrete has advantages as construction material. Externally bonded reinforcement (EBR) and near-surface mounted reinforcement (NSMR) are being studied as methods using CFRP for the strengthening of degraded concrete structures. EBR strengthens the concrete member by bonding FRP sheet or plate on the tensile side of the member. Besides, NSMR operates by embedding the FRP reinforcement together with the filler in the slot that has been first arranged in the tensile side of the concrete cover. In terms of the efficiency of FRP, NSMR is superior to EBR but both methods experience premature bond failure of the FRPconcrete interface before full development of the maximum performance of FRP [5-7].

Studies attempted to overcome such drawback by prestressing the FRP reinforcement through the addition of an anchoring device to NSMR $[8,9]$. Nordin and Täljsten [8] performed an experimental study by prestressing the CFRP (Carbon FRP) rod up to $10 \%$ and $20 \%$ of the yield strength. 

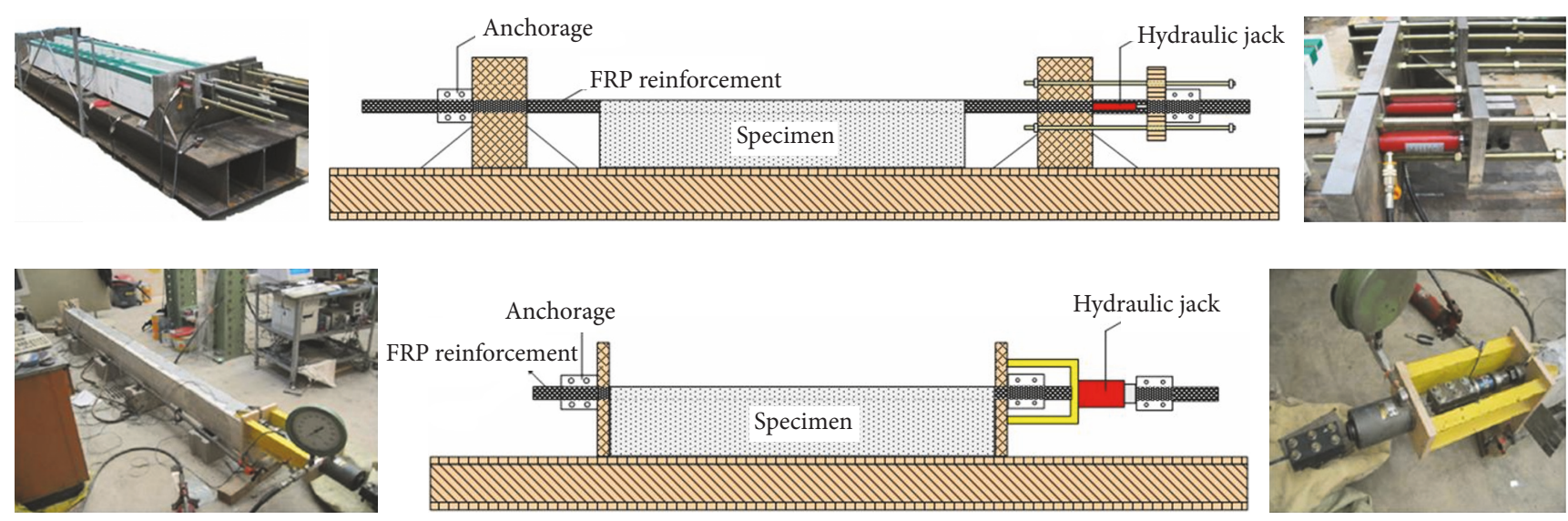

FIGURE 1: The existing prestressing system.

The test results showed that the serviceability improved with significantly increased cracking and yield loads and that the durability improved noticeably through enhanced fatigue behaviour and smaller cracks [10]. Jung et al. [9] tensioned the CFRP rod and plate up to $20 \%$ of the yield strength and compared the behaviour with that of the NSMR without prestressing. The authors reported that the introduction of prestress could delay the bond failure since the prestressed NSMR specimens failed through the rupture of the FRP reinforcement [9]. Badawi [11] compared the crack, yield, and maximum loads of the NSMR specimen without prestress to those of NSMR specimens in which the CFRP rod was prestressed up to $40 \%$ and $60 \%$ of the yield strength of the rod. The specimen with prestressing of $40 \%$ exhibited large increase of the crack, yield, and maximum loads but the specimen with prestressing of $60 \%$ experienced slight reduction of the maximum load [11].

Many structures could fail at a lower load level than their static capacity because most of them are under repeated loads. Fatigue performance of the prestressed NSMR would be governed by conventional steels because CFRP reinforcements offer higher fatigue strength as compared with steel [12]. However, Badawi and Soudki [13] reported that the increase in CFRP prestress level results in a transition of the failure mode from steel fracture to CFRP rupture. Oudah and ElHacha [14] showed that the high prestress level resulted in an increased degradation and damage accumulation because cyclic concrete creep deformation increased with the increase in the mean concrete cyclic stress.

The studies related to the prestressed NSMR focused mainly and experimentally on the prestressing force due to the absence of appropriate prestressing system for NSMR. The prestressing systems applied in these experiments were principally the pretensioning and the end-support systems. The largest disadvantage of the prestressing system is that the system cannot be removed until the filler is cured. This problem lowers the turning rate of the equipment and makes it limited to experiment, which stresses the necessity of a new prestressing system (Figure 1) [15].

Therefore, this study applies a new prestressing system which reliefs the need to wait until the curing of the filler after
TABLE 1: Summary of material properties.

\begin{tabular}{|c|c|c|}
\hline Material & Properties & \\
\hline Concrete $^{(1)}$ & Compressive strength $(\mathrm{MPa})$ & 27 \\
\hline \multirow{4}{*}{$\begin{array}{l}\text { Tension steel reinforcement } \\
(\mathrm{D} 10)^{(1)}\end{array}$} & Yield strength (MPa) & 426 \\
\hline & Tensile strength (MPa) & 562 \\
\hline & Diameter $(\mathrm{mm})$ & 9.53 \\
\hline & Area $\left(\mathrm{cm}^{2}\right)$ & 0.7133 \\
\hline \multirow{4}{*}{$\begin{array}{l}\text { Compression steel } \\
\text { reinforcement }(\mathrm{D} 13)^{(1)}\end{array}$} & Yield strength (MPa) & 481 \\
\hline & Tensile strength (MPa) & 608 \\
\hline & Diameter $(\mathrm{mm})$ & 12.7 \\
\hline & Area $\left(\mathrm{cm}^{2}\right)$ & 1.267 \\
\hline \multirow{3}{*}{ Epoxy $^{(2)}$} & Bond strength (MPa) & 3.61 \\
\hline & Compressive strength (MPa) & 112 \\
\hline & Flexural strength $(\mathrm{MPa})$ & 63.7 \\
\hline \multirow{3}{*}{$\begin{array}{l}\text { CFRP tendon } \\
{\text { (Circular type })^{(1)}}^{(\text {Circula }}\end{array}$} & Diameter $(\mathrm{mm})$ & 9.5 \\
\hline & Tensile strength (MPa) & 2500 \\
\hline & Elastic modulus (GPa) & 135 \\
\hline
\end{tabular}

(1): from tests carried out by the authors; (2): provided by supplier.

jacking to the prestressing of NSMR and examines the effect of the prestressing size and location of the anchorage on the strengthened behaviour.

\section{Experimental Program}

2.1. Manufacture of Specimens. A total of 8 simply supported $\mathrm{RC}$ beam specimens with span of $3 \mathrm{~m}$ were cast using concrete with compressive strength of $27 \mathrm{MPa}$ at 28 days with the details and cross-section shown in Figure 2. SD400 steel bars D10 $(\phi 9.53 \mathrm{~mm})$ are arranged with steel ratio of 0.0041 , one layer of three D13 bars $(\phi 12.7 \mathrm{~mm})$ is arranged as compression reinforcements, D10 shear bars are disposed every $100 \mathrm{~mm}$ in the shear zone to prevent shear failure, and CFRP tendons are used being $9.5 \mathrm{~mm}$ diameter in Figure 3. Table 1 summarizes the properties of the materials used in the test beams. 
TABLE 2: Experimental parameters.

\begin{tabular}{lcccc}
\hline Specimens & Strengthened length $(\mathrm{mm})$ & $L_{s} / L$ & Filler & Prestressing level \\
\hline Control & - & - & - & - \\
SL90-E-0 & 2700 & 0.90 & Epoxy & $0 \%$ \\
SL90-E-20 & 2700 & 0.90 & Epoxy & $20 \%$ \\
SL90-E-40 & 2700 & 0.90 & Epoxy & $40 \%$ \\
SL70-E-50 & 2100 & 0.70 & Epoxy & $50 \%$ \\
SL83-E-40 & 2500 & 0.83 & Epoxy & $40 \%$ \\
SL77-E-40 & 2300 & 0.77 & Epoxy & $40 \%$ \\
SL70-E-40 & 2100 & 0.70 & Epoxy & $40 \%$ \\
\hline
\end{tabular}

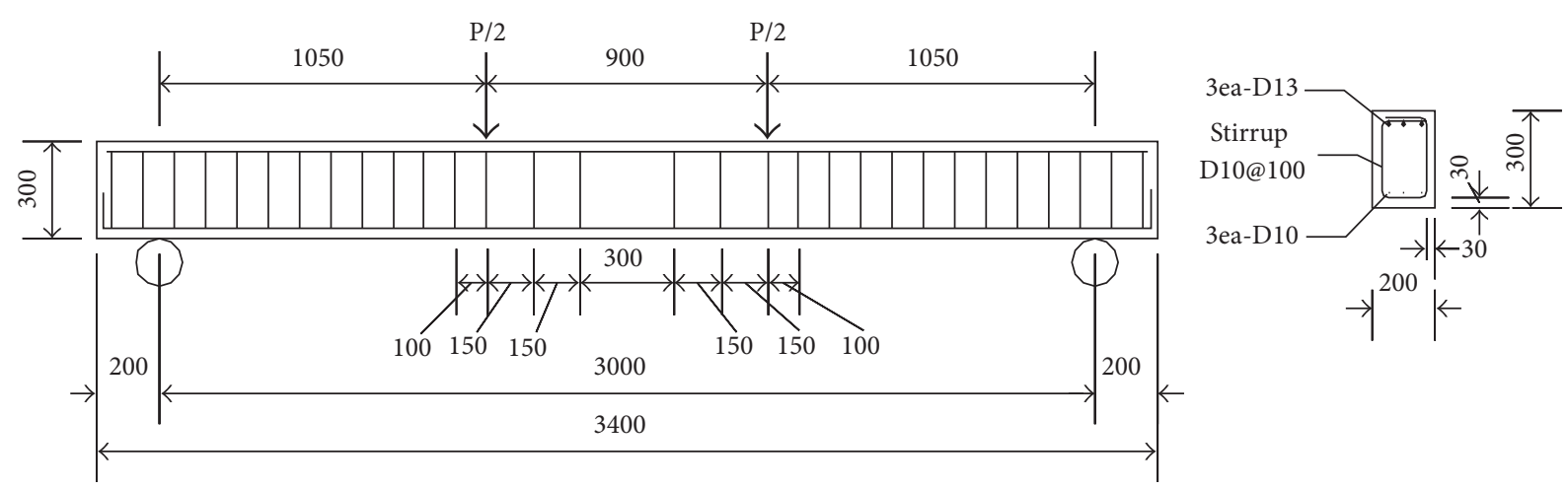

FIGURE 2: Details and cross-section of specimens (mm).

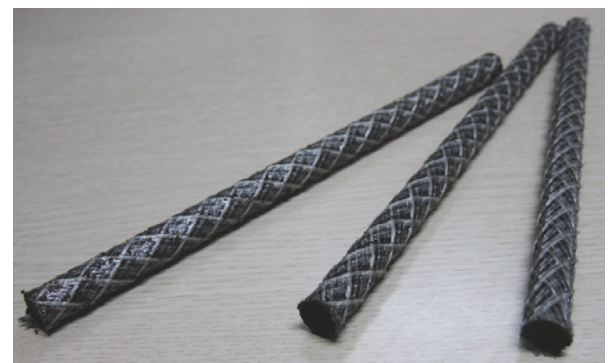

FIgURE 3: Shape of CFRP tendon.

2.2. Experimental Parameters. Since prestressed NSMR introduces prestress to improve actively the performance based upon the behaviour of NSMR, its behaviour is closely related to that of NSMR. Among the factors influencing the strengthening performance of NSMR, the length of strengthening is an important one related to the failure mode, which has been frequently adopted as test variable because it is easy to implement $[9,15]$. Even if this length of strengthening influences the strengthening performance of the NSMR including the prestressed NSMR, the research results published to date could not evaluate the effect of the length of strengthening since this length was longer than the span length due to the absence of appropriate jacking system. Therefore, research should be further on this topic.

Research also compared experimentally the strengthening performance applying inorganic cement grout [16] despite the fact that organic epoxy is mainly used as filler in current NSMR. The authors reported that cement is still inappropriate to replace epoxy and related the possible applicability of materials with superior properties like high strength mortar as replacement of epoxy. Moreover, considering the high cost of epoxy compared to mortar, need is for further investigation on the strengthening performance brought by the relatively cheaper mortar. Accordingly, this study applies a newly developed prestressing system to prestressed NSMR to conduct experiments considering the length of strengthening, the introduced prestress force (Table 2). The length of strengthening is varied from $70 \%$ to $90 \%$ of the span length and the prestress force is varied to be $0 \%, 20 \%, 40 \%$, and $50 \%$ of the tensile strength of the CFRP reinforcement. Epoxy is adopted as filler to observe the static performance and failure pattern of the specimens.

Table 2 lists the experimental parameters and corresponding designations of the specimens. The control specimen, as the beam without strengthening, was cast to compare the strengthening performance of the NSM systems. The main variables of this study are the prestressing level and the length of strengthening (Table 2). The prestressing levels correspond to $0 \%, 20 \%$, and $40 \%$ of tensile strength of the NSM CFRP tendon.

2.3. Prestressing of NSMR. Figures 4 and 5 illustrate the new prestressing system developed in this study. As shown in Figure 4(a), the CFRP tendon installed in the anchorage is fixed by fastening nuts on the anchoring plates in the fixed end and jacked end. Then, the jacking frame is installed on the anchoring plate at the jacked end to proceed prestressing 
TABLE 3: Summary of experimental results.

\begin{tabular}{|c|c|c|c|c|c|c|c|c|c|c|}
\hline & \multicolumn{4}{|c|}{ Yielding } & \multicolumn{4}{|c|}{ Maximum } & \multirow[b]{2}{*}{ Failure mode } & \multirow[b]{2}{*}{$d_{u} / d$} \\
\hline & $\begin{array}{c}M_{y} \\
\mathrm{kNmm}\end{array}$ & $\begin{array}{l}P_{y} \\
\mathrm{kN}\end{array}$ & $\begin{array}{c}d_{y} \\
\mathrm{~mm}\end{array}$ & $P / P_{y \text { con }}$ & $\begin{array}{c}M_{u} \\
\mathrm{kNmm}\end{array}$ & $\begin{array}{l}P_{u} \\
\mathrm{kN}\end{array}$ & $\begin{array}{c}d_{u} \\
\mathrm{~mm}\end{array}$ & $P / P_{u \text { con }}$ & & \\
\hline Control-27 MPa & 23006 & 43.82 & 11.52 & 1 & 25799 & 49.14 & 46.49 & 1 & $\mathrm{a}$ & 4.03 \\
\hline SL90-E-0 & 33448 & 63.71 & 13.82 & 1.45 & 59220 & 112.8 & 61.89 & 2.3 & $\mathrm{~b}$ & 4.48 \\
\hline SL90-E-20 & 41528 & 79.1 & 15.36 & 1.81 & 62543 & 119.13 & 53.78 & 2.42 & $\mathrm{~b}$ & 3.5 \\
\hline SL90-E-40 & 47345 & 90.18 & 16.08 & 2.06 & 62029 & 118.15 & 38.46 & 2.4 & $\mathrm{~b}$ & 2.39 \\
\hline SL70-E-50 & 52889 & 100.74 & 18.09 & 2.3 & 62606 & 119.25 & 38.48 & 2.43 & $b, c$ & 2.13 \\
\hline SL83-E-40 & 49009 & 93.35 & 15.5 & 2.13 & 67032 & 127.68 & 43.04 & 2.6 & $\mathrm{~b}$ & 2.78 \\
\hline SL77-E-40 & 48269 & 91.94 & 17.83 & 2.1 & 67872 & 129.28 & 46.37 & 2.63 & c & 2.6 \\
\hline SL70-E-40 & 48878 & 93.1 & 17.99 & 2.12 & 60344 & 114.94 & 45.09 & 2.34 & $\mathrm{c}$ & 2.51 \\
\hline
\end{tabular}

a: flexural failure; b: rupture of CFRP tendon; c: increased cracking of anchor plate.

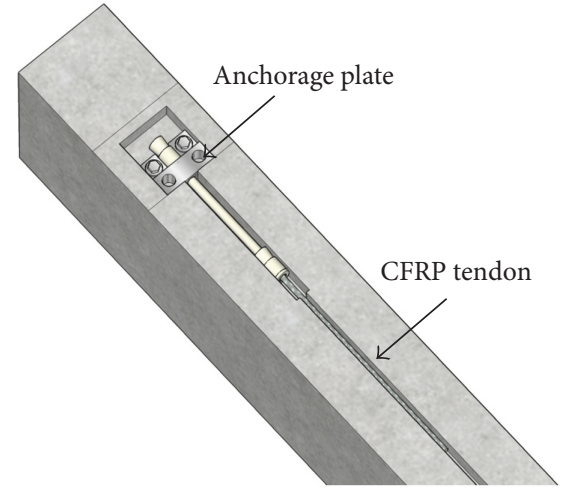

(a)

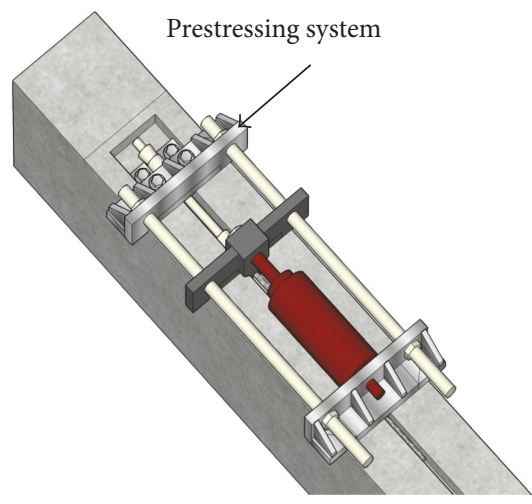

(b)

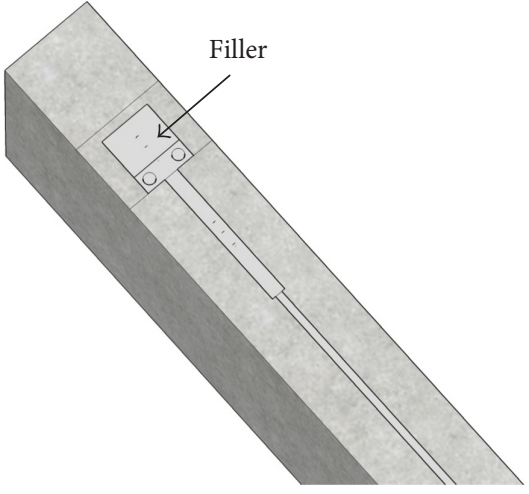

(c)

FIGURE 4: Concept of the new prestressing system developed in this study.
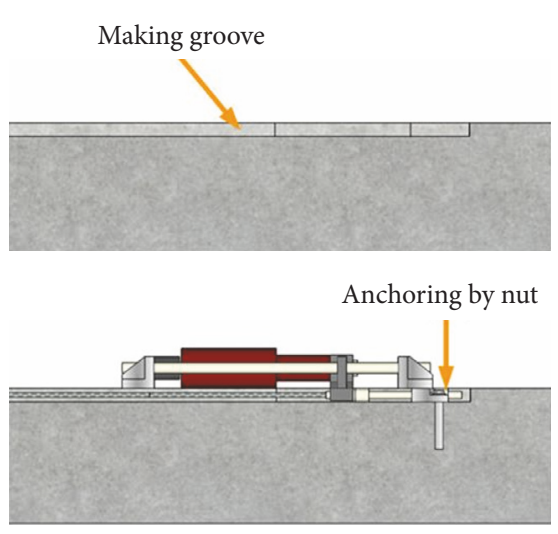

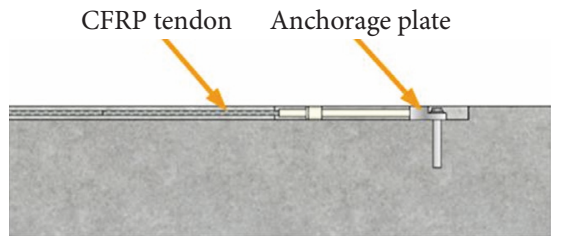

Removing prestressing system

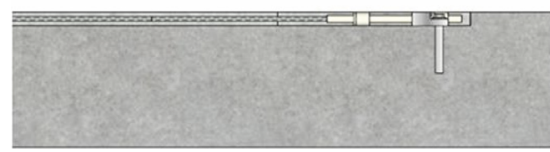

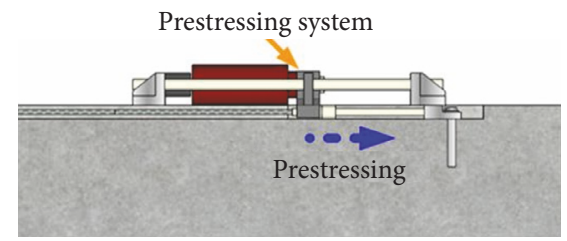

Filling \& curing filler

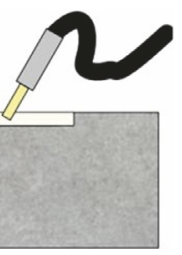

FIGURE 5: Application of the new prestressing system.

after having installed the hydraulic cylinder as shown in Figure 4(b). Thereafter, the anchored end of the CFRP tendon is nut-fastened and prestressing is completed by removing the pressure of the hydraulic cylinder. Finally, the anchorage is dismantled before filling the groove with the filler and curing the filler (Figure 4(c)).

2.4. Loading and Measurement Methods. All the specimens were subjected to 4-point bending tests up to failure by means of a UTM (Universal Testing Machine) with capacity of
$980 \mathrm{kN}$. The loading was applied under displacement control at speed of $0.02 \mathrm{~mm} / \mathrm{sec}$ until the first $10 \mathrm{~mm}$ and $0.05 \mathrm{~mm} / \mathrm{sec}$ from $10 \mathrm{~mm}$ until failure. The test data were recorded by a static data logger and a computer at intervals of 1 second. Electrical resistance strain gauges were fixed at mid-span and $L / 4$ to measure the strain of steel reinforcements.

\section{Experimental Results}

3.1. Failure Modes and Strengthening Performances. Table 3 arranges the experimental results. 


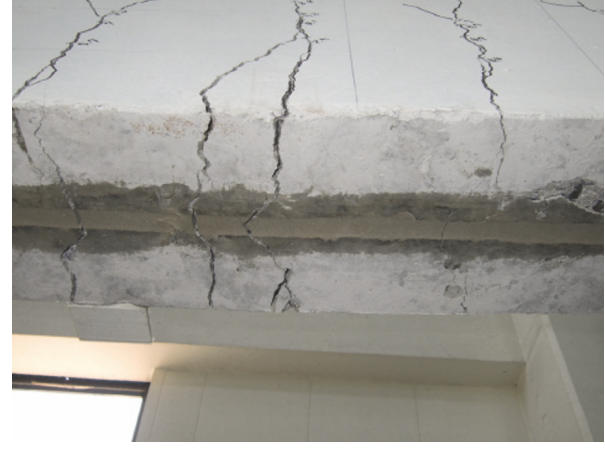

FIGURE 6: Rupture of CFRP tendon (SL90-E-40).

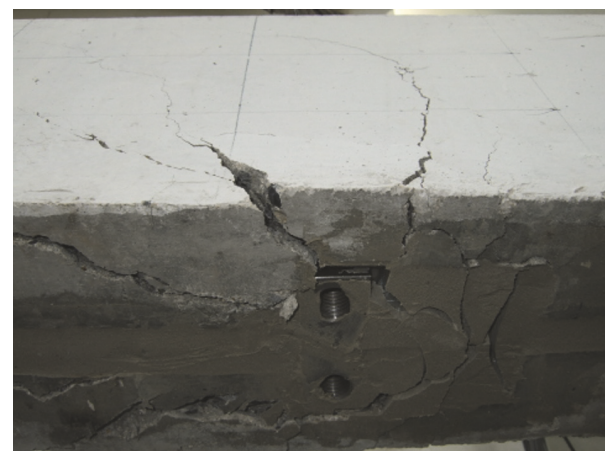

FIGURE 7: Cracking of anchor plate (SL70-E-40).

The moment, load, and deflection are represented for each rebar yielding and maximum load. $\mathrm{P} / \mathrm{P}$ _con, the load ratio of strengthened specimen to the nonstrengthened specimen (CONTROL), indicates the strengthening effect. $d_{u} / d_{y}$, the deflection ratio of maximum to yielding, shows the ductility of specimen. The control specimen exhibited common flexure failure occurring through compressive failure of the upper concrete after yielding of the reinforcement. Besides, the prestressed NSM specimens experienced two types of failure mode: by rupture of the CFRP tendon after yielding of the steel reinforcement (SL90, SL83, Figure 6) and by increase of the cracks around the anchor plate (SL77, SL70, Figure 7).

3.2. Strengthening Performance. Figure 8 plots the loaddeflection curves according to the level of prestress. The crack load and yield load are seen to increase with higher level of prestress. Since the rupture of the CFRP tendon determines the member performance, similar maximum load can be observed regardless of the level of prestress and the ductility appears to reduce. In view of the strengthening performance with respect to the level of prestress, the yield load and the maximum load are seen to increase, respectively, by $45 \%$ to $130 \%$ and by $113 \%$ to $143 \%$ compared to the control specimen.

Figure 9 compares the load-deflection curves according to the length of strengthening. Since all the considered specimens were prestressed up to $40 \%$ of the tensile strength of the CFRP tendon, similar crack load, yield load, and maximum load can be observed. The ductility tends to reduce with reference to specimen SL83 and can be attributed to

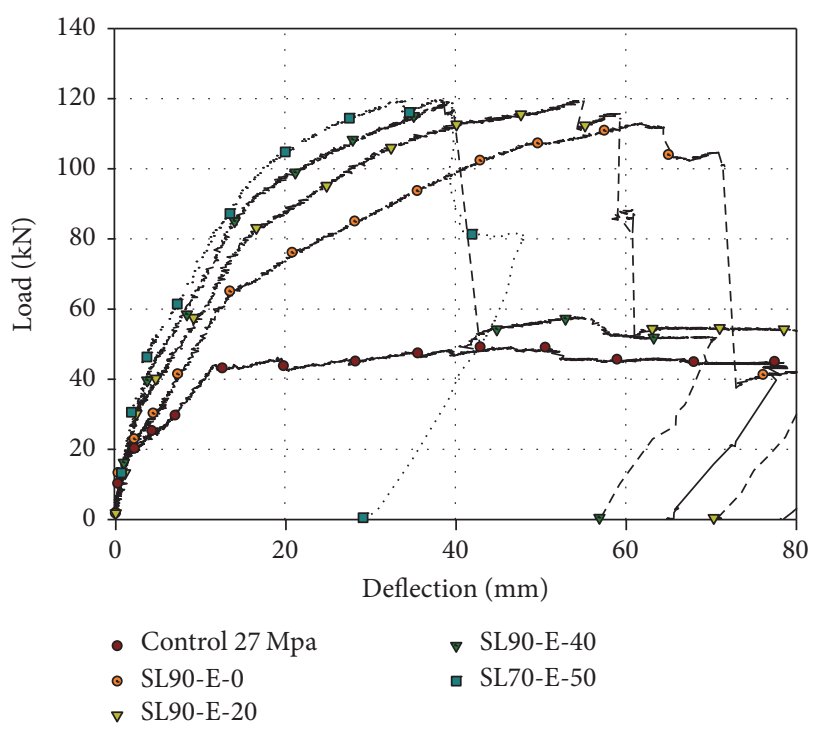

FIgURE 8: Experimental load-deflection curves.

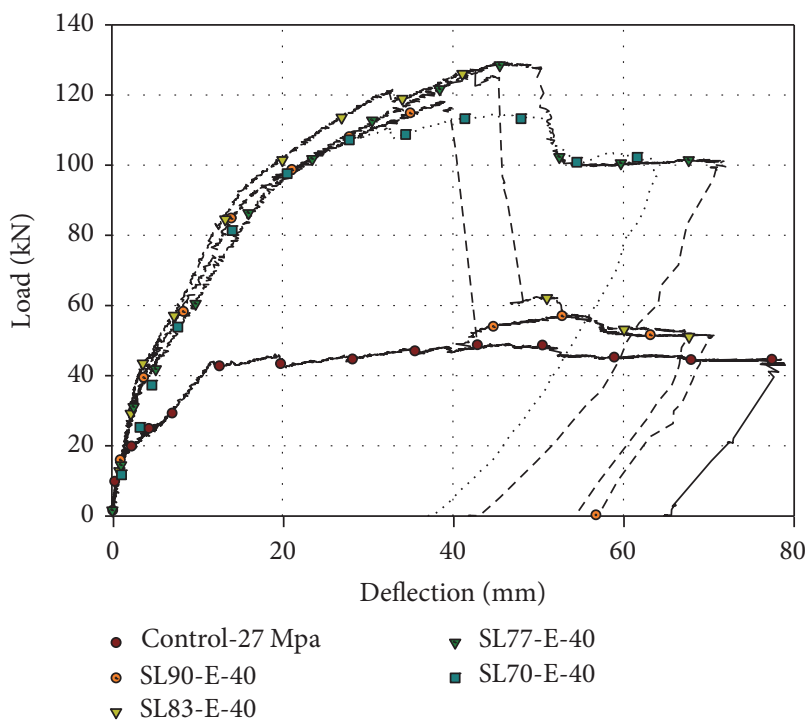

FIGURE 9: Experimental load-deflection curves.

the occurrence of cracks around the anchor plate. If the location of the anchor plate falls outside the effective depth $d_{s}$ and the length of strengthening shortens, the cracks increase around the anchor plate after yielding of the tensile steel and appears to lower the maximum load since the anchor becomes insufficient for the rupture of the CFRP tendon.

\section{Analytical and Experimental Results}

4.1. Section Analysis of Specimens Reinforced by Prestressed NSMR. Numerous researchers proposed bond failure models to predict the behaviour of the specimens reinforced by NSMR [16-18]. However, for the prestressed NSMR with anchorage, it is impossible to predict the behaviour by section analysis without a complex bond failure model since rupture 


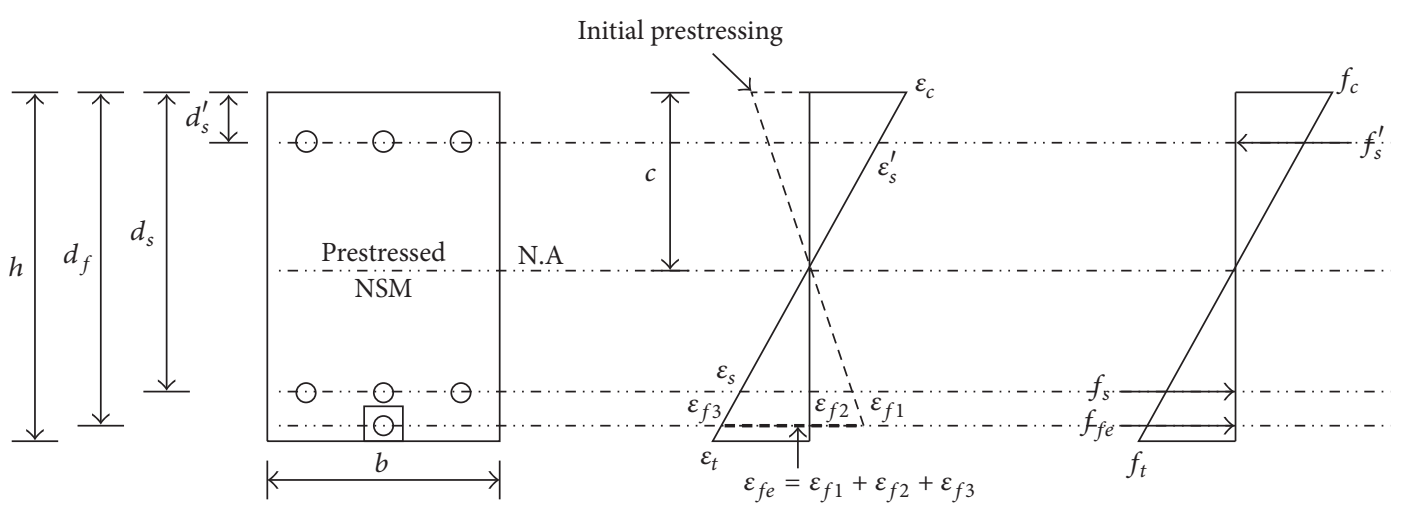

(a)

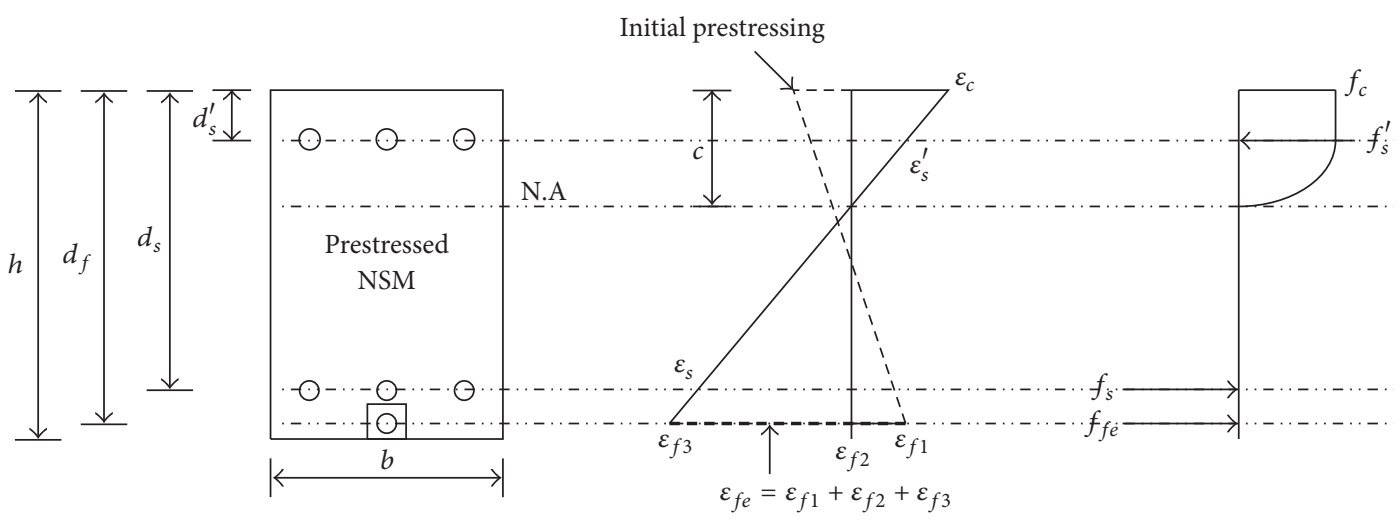

(b)

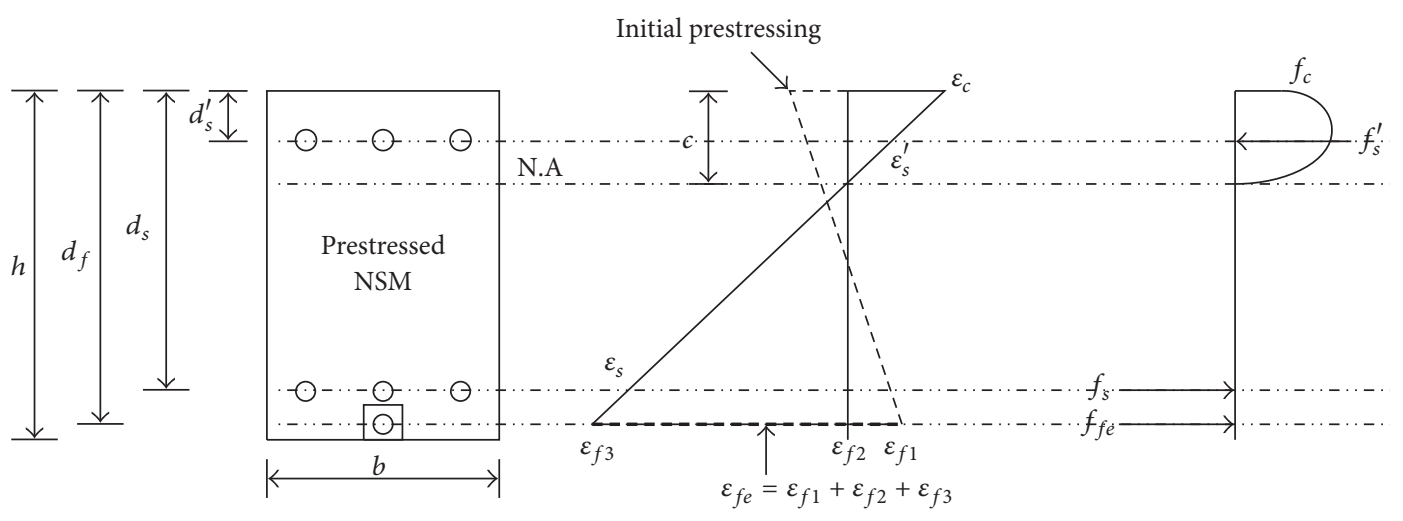

(c)

FIGURE 10: Load-deflection curves per analysis stage.

of the CFRP tendon occurs when reaching the maximum performance of the material.

Accordingly, this study conducts section analysis using the strain compatibility and force equilibrium conditions for further comparison with the experimental behaviour of the specimens strengthened by prestressed NSMR. The momentcurvature distribution of the normal concrete specimens can be subdivided into three stages limited by the initiation of cracking and the yielding of steel. Therefore, section analysis is also conducted by distinguishing the working moment by means of the load for the stages before cracking, after cracking and before yielding of steel, and after yielding of steel $[11,19]$.
The calculation at each stage uses the equilibrium conditions of the forces and moments. Figure 10 depicts the distribution of the strain and stress at each stage.

(a) Precracking stage is as follows: $0 \leq M_{a} \leq M_{c r}$

$$
\begin{aligned}
& \frac{1}{2} f_{c} b c+A_{s}^{\prime} f_{s}^{\prime}-\frac{1}{2}(h-c) f_{c t} b-A_{s} f_{s}-A_{f} f_{f e}=0 \\
& M_{a} \\
& \quad=\frac{1}{3} f_{c t} b h(h-c)+A_{s} f_{s}\left(d_{s}-\frac{1}{3} c\right) \\
& \quad+A_{f} f_{f e}\left(d_{f}-\frac{1}{3} c\right)-A_{s}^{\prime} f_{s}^{\prime}\left(\frac{1}{3} c-d_{s}^{\prime}\right) .
\end{aligned}
$$




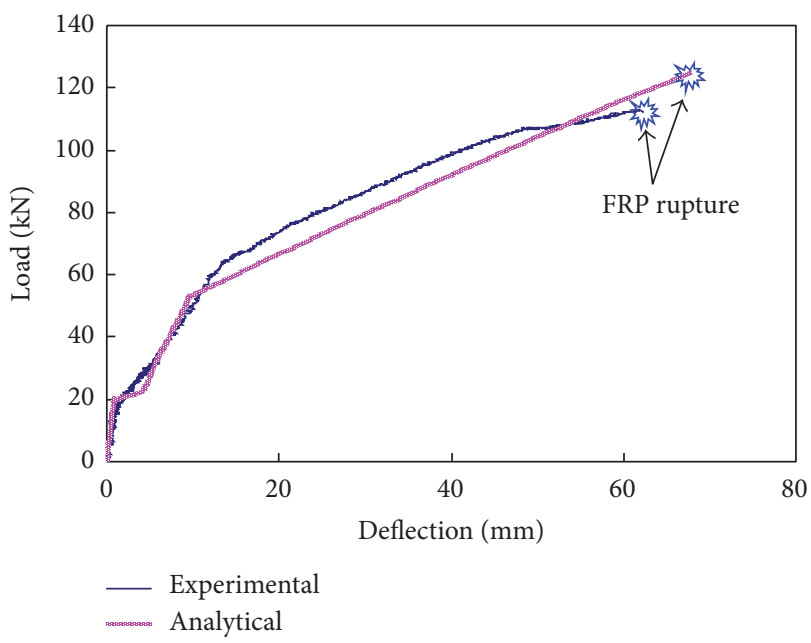

(a) SL90-E-0

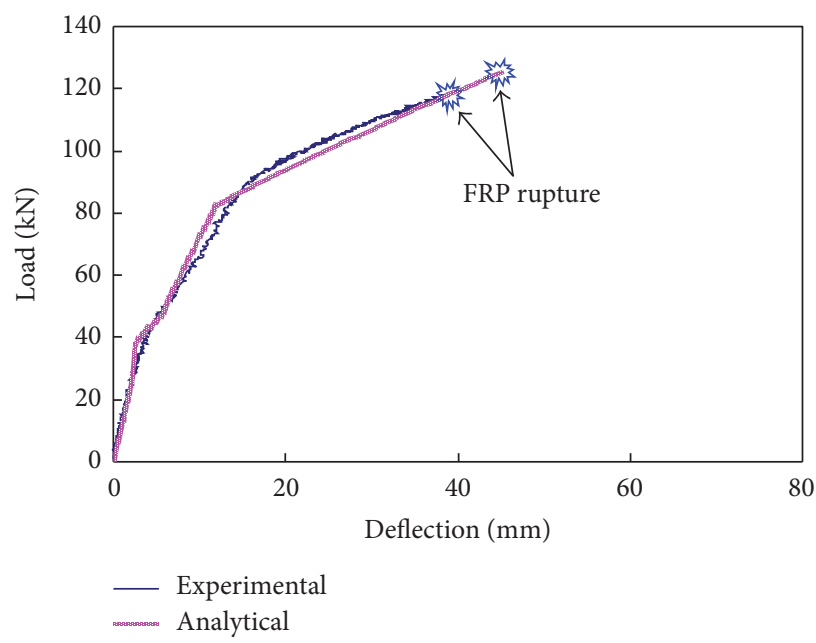

(c) SL90-E-40

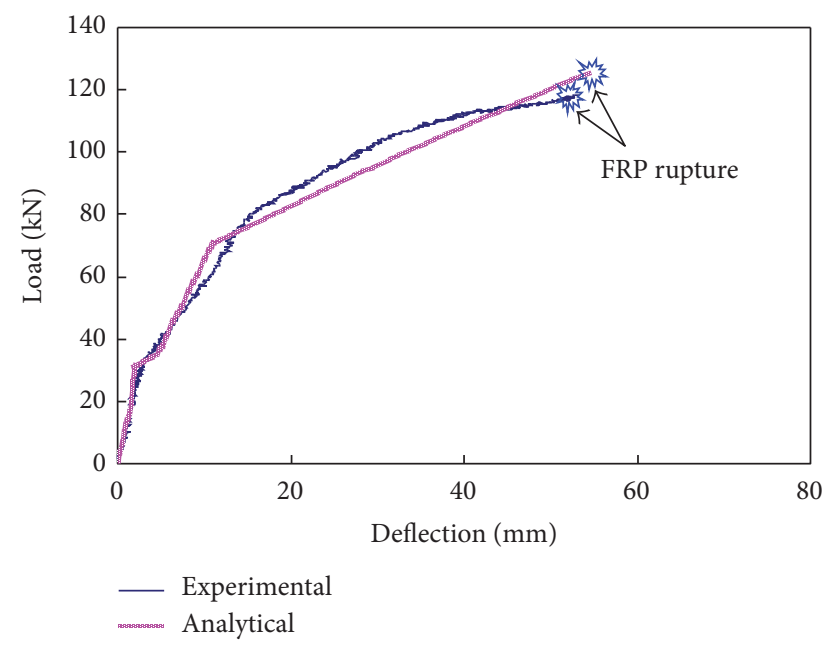

(b) SL90-E-20

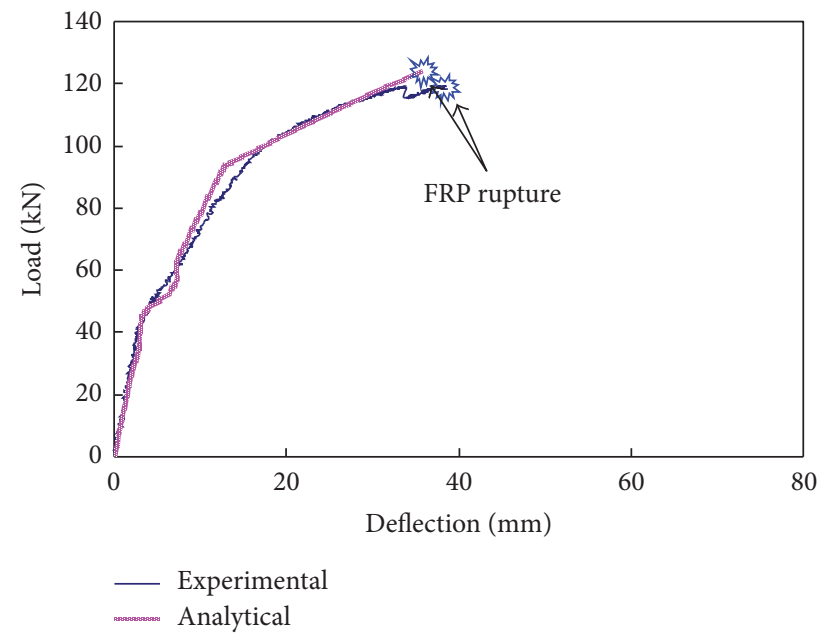

(d) SL70-E-50

FIgURE 11: Comparison of experimental and analytical load-deflection curves.

(b) Preyielding stage is as follows: $M_{c r} \leq M_{a} \leq M_{y}$

$$
\begin{aligned}
& \alpha_{1} \beta_{1} f_{c k} b c+A_{s}^{\prime} f_{s}^{\prime}-A_{s} f_{s}-A_{f} f_{f e}=0 \\
& M_{a} \\
& \quad=A_{s} f_{s}\left(d_{s}-\frac{1}{2} \beta_{1} c\right)+A_{f} f_{f e}\left(d_{f}-\frac{1}{2} \beta_{1} c\right) \\
& \quad-A_{s}^{\prime} f_{s}^{\prime}\left(\frac{1}{2} \beta_{1} c-d_{s}^{\prime}\right) .
\end{aligned}
$$

(c) Postyielding stage is as follows: $M_{y} \leq M_{a} \leq M_{u}$

$$
\begin{aligned}
& \alpha_{1} \beta_{1} f_{c k} b c+A_{s}^{\prime} f_{s}^{\prime}-A_{s}\left[f_{y}+E_{s}^{\prime}\left(\varepsilon_{s}-\varepsilon_{y}\right)\right]-A_{f} f_{f e} \\
& \quad=0 \\
& M_{a} \\
& \quad=A_{s}\left[f_{y}+E_{s}^{\prime}\left(\varepsilon_{s}-\varepsilon_{y}\right)\right]\left(d_{s}-\frac{1}{2} \beta_{1} c\right) \\
& \quad+A_{f} f_{f e}\left(d_{f}-\frac{1}{2} \beta_{1} c\right)-A_{s}^{\prime} f_{s}^{\prime}\left(\frac{1}{2} \beta_{1} c-d_{s}^{\prime}\right) .
\end{aligned}
$$

4.2. Calculation Process. The calculation determines the deflection, the strain of each material, the loads, and the position of the neutral axis by the strain compatibility condition while increasing the strain of steel, by the constitutive equations of each material, and by the equilibrium of the internal forces. The final failure mode is decided to be the compressive failure of concrete if the compressive strain of the concrete at the top exceeds 0.003 or the rupture of the CFRP tendon when exceeding the rupture strain of CFRP.

4.3. Comparison of Analytical and Experimental Results. Figures 11 and 12 compare the analytical and experimental results with respect to the level of prestress. The analytical prediction of the load-deflection relation is seen to be in good agreement with the experimental results for the specimens strengthened by NSMR with prestress levels up to $0 \%, 20 \%, 40 \%$, and $50 \%$. In particular, the maximum load of the specimens with prestress levels of $20 \%, 40 \%$, and $50 \%$ is predicted within an error running between $4 \%$ and $6 \%$. Besides, the maximum load of the specimen with $0 \%$ of prestress is predicted with 


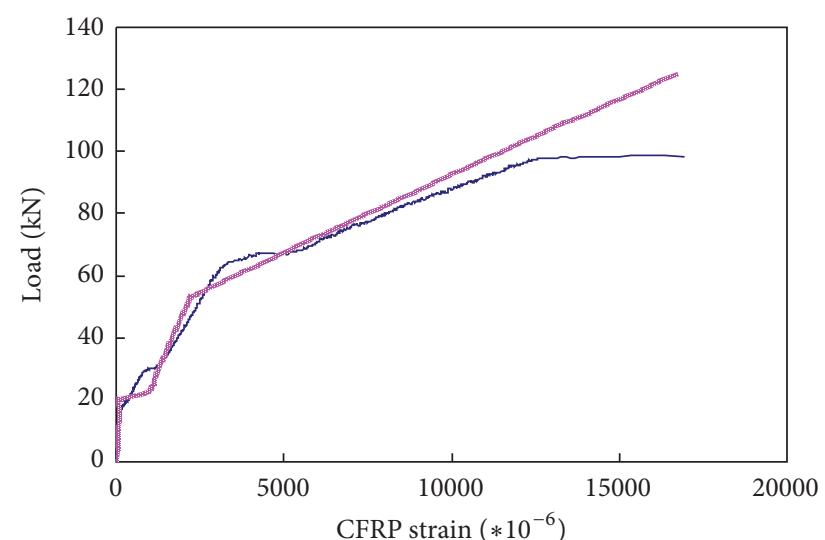

- Experimental

-..-. Analytical

(a) SL90-E-0

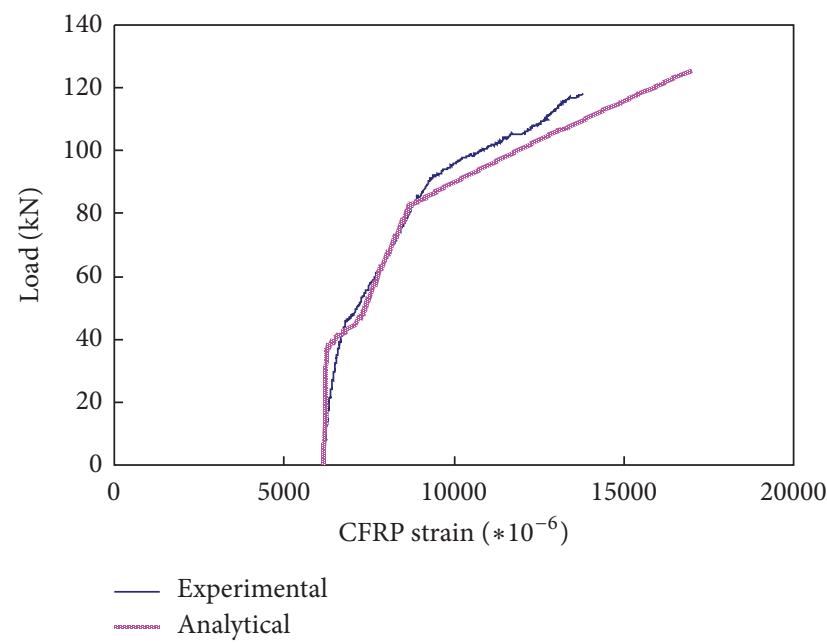

(c) SL90-E-40

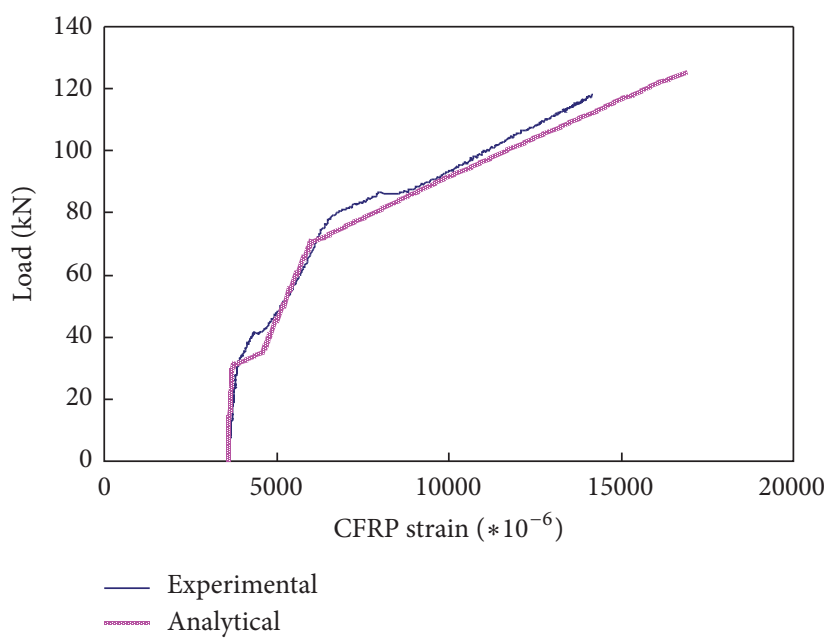

(b) SL90-E-20

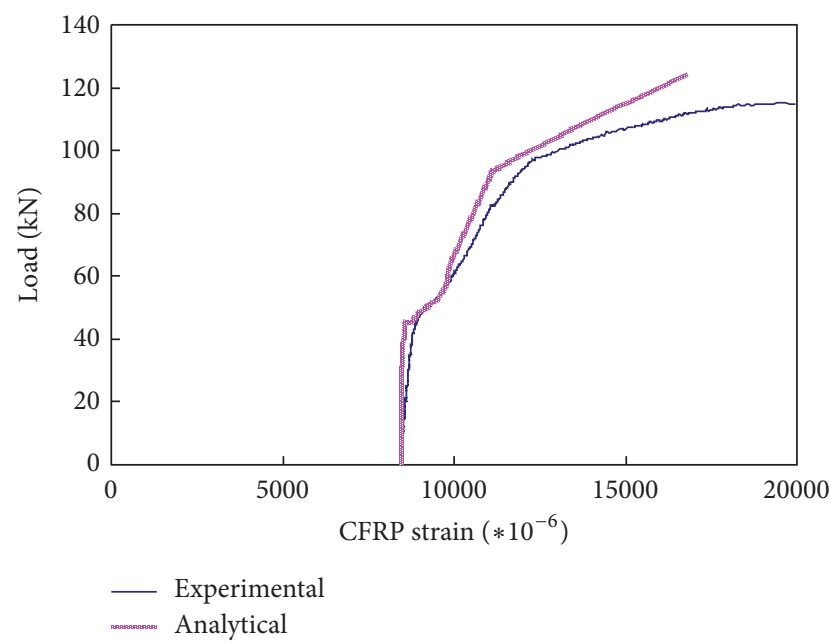

(d) SL70-E-50

FIGURE 12: Comparison of experimental and analytical load-strain curves.

an error between $6 \%$ and $8 \%$. This slightly larger error is due to the occurrence of local failure at the bottom concrete under the loaded point (Figure 12(a)).

\section{Conclusions}

This study examined the flexural behaviour of specimens strengthened by prestressed NSM CFRP tendon. The following conclusions can be drawn:

(1) The crack and yield loads increased with higher level of prestress but the ductility tended to reduce. The specimens in which failure occurred through the rupture of the CFRP tendon showed similar maximum load.

(2) The analysis of the failure mode with respect to the length of strengthening showed that the failure pattern and cracking pattern varied according to the position of the anchor plate. Flexural failure could be induced by installing the anchor plate closest to the support. The experimental results revealed that the anchor plate should be installed within the effective depth $d_{s}$ to minimize the occurrence of shear-induced diagonal cracks. The test results also indicated that the length ratio of strengthening should be larger than $83 \%$ to prevent the occurrence of bond failure at the end of the reinforcement.

(3) The comparison of the analytical and experimental results showed that the section analysis could predict the maximum load of the specimens strengthened by prestressed NSMR within an error between $4 \%$ and $6 \%$.

\section{Conflicts of Interest}

The authors declare that they have no conflicts of interest. 


\section{Acknowledgments}

This research was supported by a grant from "a Strategic Research Project funded by the Korea Institute of Civil Engineering and Building Technology" and "Upgrading Technology of Prestressed NSM Reinforcement System with CFRP Tendon.”

\section{References}

[1] M. Rezazadeh, H. Ramezansefat, and J. Barros, "NSM CFRP prestressing techniques with strengthening potential for simultaneously enhancing load capacity and ductility performance," Journal of Composites for Construction, vol. 20, no. 5, Article ID 04016029, 2016.

[2] W. T. Jung, J. S. Park, and Y. H. Park, "An experimental study on application of new prestressing system for NSM strengthening technique," in Proceedings of the 9th International Symposium on Fiber Reinforced Polymer Reinforcement for Reinforced Concrete Structures (FRPRCS'09), 2009.

[3] W.-T. Jung, J.-S. Park, and S.-H. Kim, "A study on the behavior characteristics of curved FRP-concrete composite panel," Advanced Materials Research, vol. 557-559, pp. 375-380, 2012.

[4] J. S. Park, Y. H. Park, I. J. Kwak, W. T. Jung, and S. Y. Choi, "A Study on FRP Cable System for Cable Stayed Bridge," R\&D Report 08 Super-Long Span Bridge C02-01, Korea Institute of Construction Technology, 2011.

[5] W. Jung, J. Park, J. Kang, and M. Keum, "Flexural behavior of concrete beam strengthened by near-surface mounted cfrp reinforcement using equivalent section model," Advances in Materials Science and Engineering, vol. 2017, pp. 1-16, 2017.

[6] R. EI-Hacha, "Effectiveness of near surface mounted frp reinforcement for flexural strengthening of reinforced concrete beams," in Proceedings of the 4th International Conference on Advanced Composite Materials in Bridges and Structures, Alberta, Canada, 2004.

[7] L. De Lorenzis and J. G. Teng, "Near-surface mounted FRP reinforcement: an emerging technique for strengthening structures," Composites Part B: Engineering, vol. 38, no. 2, pp. 119-143, 2007.

[8] H. Nordin and B. Täljsten, "Concrete beams strengthened with prestressed near surface mounted CFRP," Journal of Composites for Construction, vol. 10, no. 1, pp. 60-68, 2006.

[9] W. T. Jung, Y. H. Park, and J. S. Park, "A study on the flexural behavior of reinforced concrete beams strengthened with NSM prestressed CFRP reinforcements," in Proceedings of the 8th International Symposium on FRP Reinforcement for Concrete Structures (FRPRCS'08), Patras, Greece, 2007.

[10] H. Nordin, Flexural Strengthening of Concrete Structures with Prestressed Near Surface Mounted CFRP Rods, Lulea University of Technology, 2003.

[11] M. A. Badawi, Monotonic and Fatigue Flexural Behaviour of RC Beams Strengthened with Prestressed NSM CFRP Rods [Ph.D. thesis], University of Waterloo, Waterloo, Ontario, Canada, 2007.

[12] R. El-Hacha and K. Soudki, "Prestressed near-surface mounted fibre reinforced polymer reinforcement for concrete structures - A review," Canadian Journal of Civil Engineering, vol. 40, no. 11, pp. 1127-1139, 2013.

[13] M. Badawi and K. Soudki, "Fatigue behavior of RC beams strengthened with NSM CFRP rods," Journal of Composites for Construction, vol. 13, no. 5, pp. 415-421, 2009.
[14] F. Oudah and R. El-Hacha, "Performance of RC beams strengthened using prestressed NSM-CFRP strips subjected to fatigue loading," Journal of Composites for Construction, vol. 16, no. 3, pp. 300-307, 2012.

[15] KICT, "Development of Bridge Strengthening Methods using Prestressed FRP Composites," Tech. Rep., 2015.

[16] T. Hassan and S. Rizkalla, "Investigation of bond in concrete structures strengthened with near surface mounted carbon fiber reinforced polymer strips," Journal of Composites for Construction, vol. 7, no. 3, pp. 248-257, 2003.

[17] M. Blaschko, "Bond Behavior of Strips Glued into Slits," in FRPRCS-6, pp. 205-214, World Scientific, Singapore, 2003.

[18] W. T. Jung, Flexural Behavior of Reinforced Concrete Beams Strengthened with NSM CFRP Reinforcements Considering the Equivalent Section [Ph.D. thesis], Myongji University, Seoul, Korea, 2009.

[19] J. S. Park, W. T. Jung, Y. H. Park, and C. Y, “The analysis for reinforced concrete beams strengthened with externally unbonded prestressed CFRP plates," Journal of the Korea Society of Civil Engineers, vol. 28, no. 4A, pp. 439-445, 2008. 

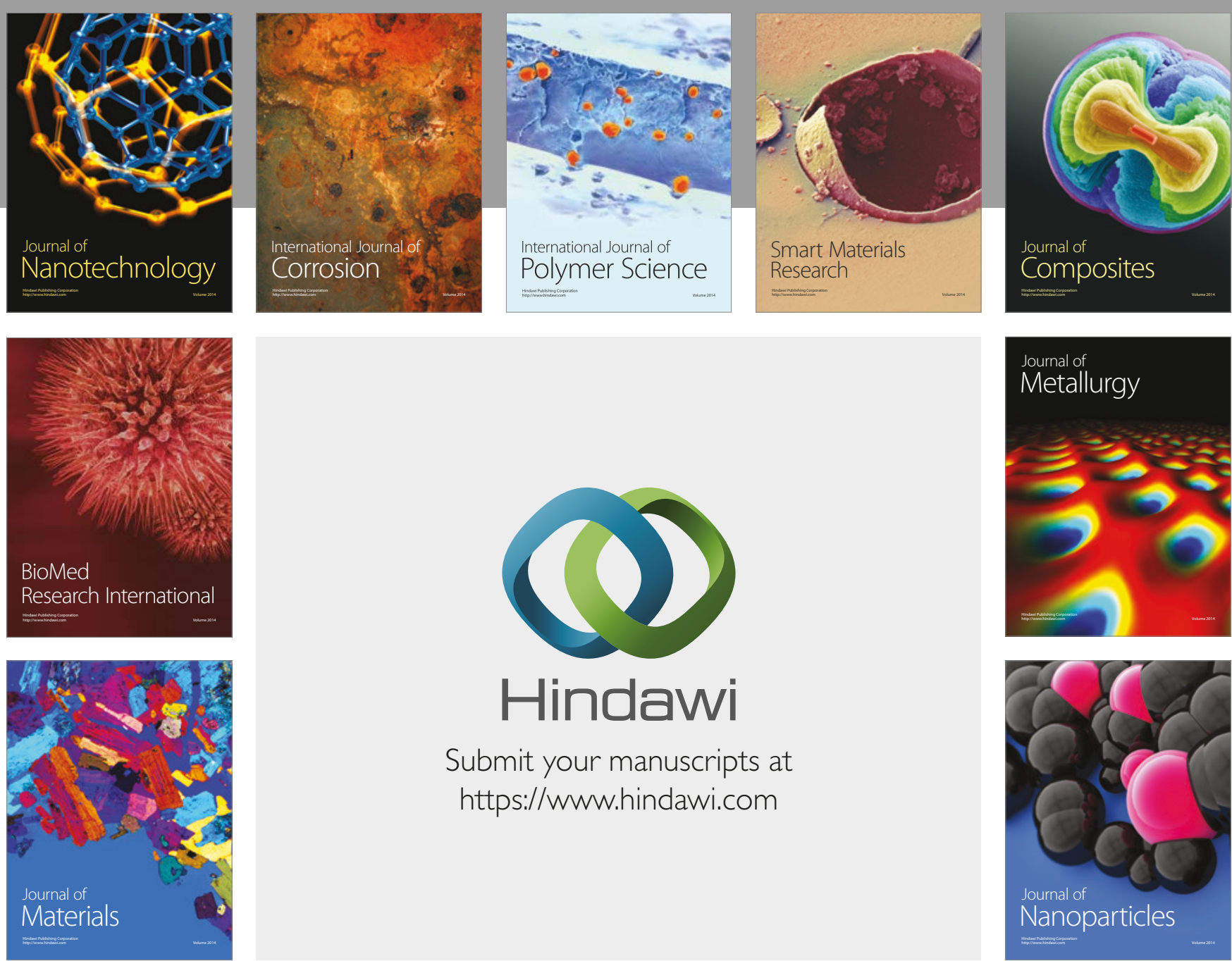

\section{Hindawi}

Submit your manuscripts at

https://www.hindawi.com
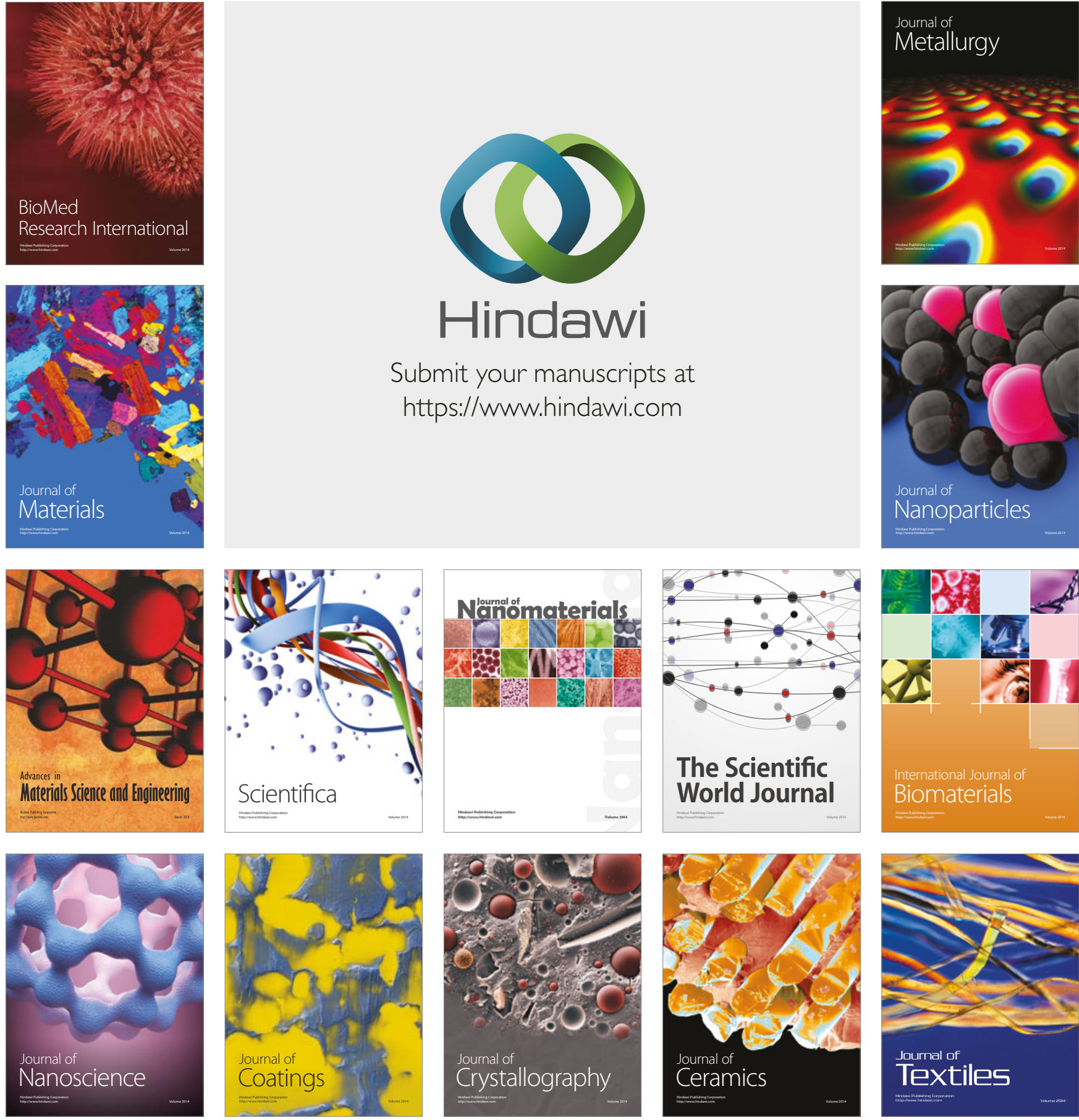

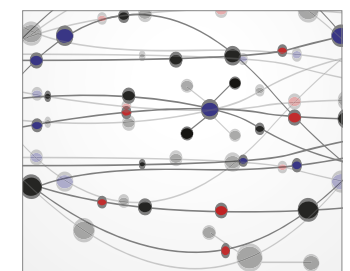

The Scientific World Journal
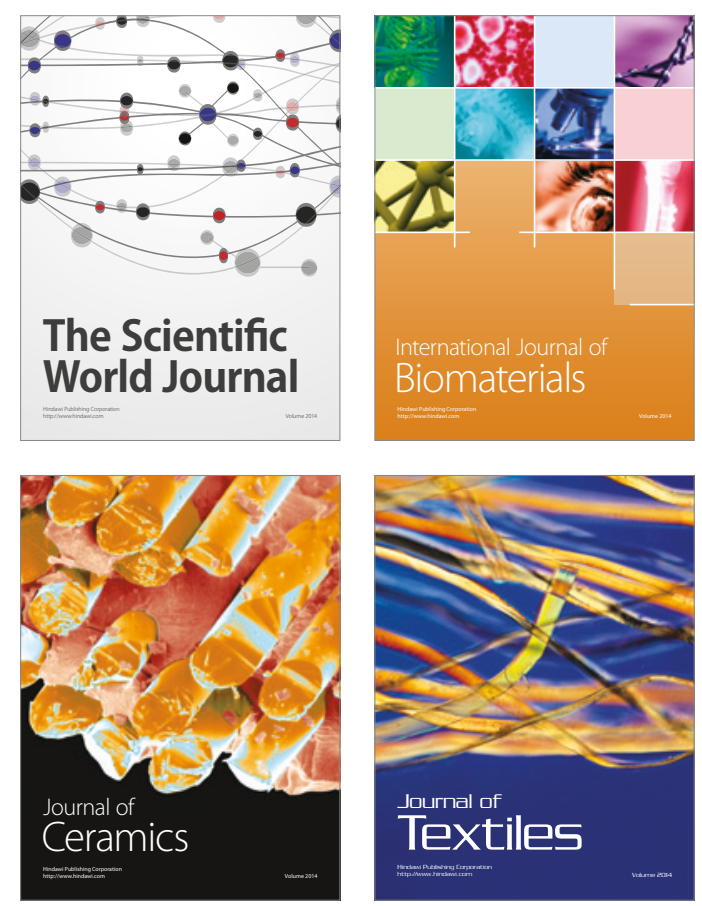